\title{
Pengaruh Kinerja Keuangan Terhadap Return Saham Perusahaan Badan Usaha Milik Negara
}

Studi Pada Perusahaan BUMN Yang Terdaftar Di BEI Periode 2015-2019

\author{
Alfi Widiana dan Rahmawati Hanny Yustrianthe \\ Akademi Akuntansi YKPN Yogyakarta \\ Email: alfi.widiana@gmail.com dan rahmahanny@gmail.com
}

Submitted: OKTOBER 2020

Accepted: DESEMBER 2020

\begin{abstract}
This objective of this research is to investigate the influence of current ratio, cash ratio, debt ratio to stock returns. The sample is selected by purposive sampling method, ie sampling technique using a certain considerations that are relevant to the selected sample research purposes. The number of samples obtained are 20 BUMN companies listed on the Indonesia Stock Exchange. The results of this study indicate tha the current ratio and cash ratio as a measurement of financial performance have a positive and significant effect on stock returns. While the debt ratio has a negative and insignificant effect on stock returns.
\end{abstract}

Keywords : Financial Performance, Financial Ratios, Stock Return.

\begin{abstract}
ABSTRAK
Penelitian ini bertujuan untuk menganalisa pengaruh current ratio, cash ratio, debt ratio terhadap return saham. Penentuan sampel dilakukan dengan menggunakan metode purposive sampling, yaitu teknik sampling dengan menggunakan pertimbangan dan batasan tertentu sehingga sampel yang dipilih relevan dengan tujuan penelitian. Jumlah sampel yang diperoleh sebanyak 20 perusahaan BUMN yang terdaftar di Bursa Efek Indonesia. Data dianalisis dengan analisis deskriptif dan analisis regresi berganda. Hasil dari penelitian ini mengindikasikan bahwa current ratio dan cash ratio sebagai pengukuran kinerja keuangan memiliki pengaruh positif dan signifikan terhadap return saham. Sedangkan debt ratio berpengaruh negatif dan tidak signifikan terhadap return saham.
\end{abstract}

Kata Kunci : Kinerja Keuangan, Rasio Keuangan, Return Saham

\section{PENDAHULUAN}

Pasar modal merupakan sarana untuk melakukan investasi yaitu memungkinkan para pemodal (investor) untuk melakukan diversifikasi investasi, membentuk portofolio sesuai dengan resiko yang bersedia mereka tanggung dengan tingkat keuntungan yang diharapkan. Investasi pada sekuritas juga bersifat likuid (mudah dirubah). Oleh karena itu, penting bagi perusahaan untuk selalu memperhatikan kepentingan para pemilik modal dengan jalan memaksimalkan nilai perusahaan. Perusahaan dapat menawarkan saham-saham dan obligasi-obligasi di pasar modal dengan tujuan mendapatkan modal dari investor. Tujuan investor atau pemodal membeli saham di pasar modal adalah mengharapkan dividen (pembagian laba) yang ia terima setiap tahunnya danreturn(keuntungan), seperti yang dikatakan oleh Robert Ang (1997: 202) bahwa tanpa adanya keuntungan yang dapat dinikmati dari suatu investasi tentunya investor tidak mau berinvestasi jika pada akhirnya tidak ada hasil.

Return merupakan hasil yang diperoleh dari investasi. Kemampuan perusahaan untuk menghasilkan laba dan kegiatan operasinya merupakan fokus utama dalam penilaian prestasi perusahaan (analisis fundamental perusahaan), karena laba perusahaan

\section{JIAKES}

Jurnal Ilmiah Akuntansi Kesatuan ol. 8 No. 3, 2020 pg. $425-432$
IBI Kesatuan ISSN 2337 - 7852 E-ISSN 2721 - 3048 
Financial

Performance and Stock Return

$\underline{426}$ selain merupakan indikator kemampuan perusahaan dalam memenuhi kewajiban bagi para penyandang dananya, juga merupakan elemen dalam menciptakan nilai perusahaan yang menunjukkan prospek perusahaan dimasa yang akan datang. Tingkat Likuiditas perusahaan pada analisis fundamental biasanya diukur dari beberapa aspek, yaitu berdasarkan Rasio Lancar (Current Ratio), Rasio Kas (Cash Ratio), dan rasio solvabilitas perusahaan yaitu menggunakan Rasio Hutang (Debt Ratio). Angka ratio bisa digunakan untuk mengukur kinerja perusahaan. Untuk dapat mengukur atau menentukan hal-hal tersebut diperlukan alat pembanding dan ratio dalam industri sebagai keseluruhan yang sejenis, dimana perusahaan menjadi anggotanya yang dapat digunakan sebagai alat pembanding dari angka ratio perusahaan, salah satu ratio yang biasa digunakan adalah Rasio Lancar (Current Ratio) adalah salah satu bentuk digunakan adalah Rasio Lancar (Current Ratio) adalah salah satu bentuk dari rasio likuiditas untuk mengukur kemampuan perusahaan dalam menutupi kewajiban jangka pendeknya menggunakan aktiva lancar nya . Setelah biaya-biaya modal (biaya yang digunakan mendanai aktiva) dikeluarkan dari analisis.

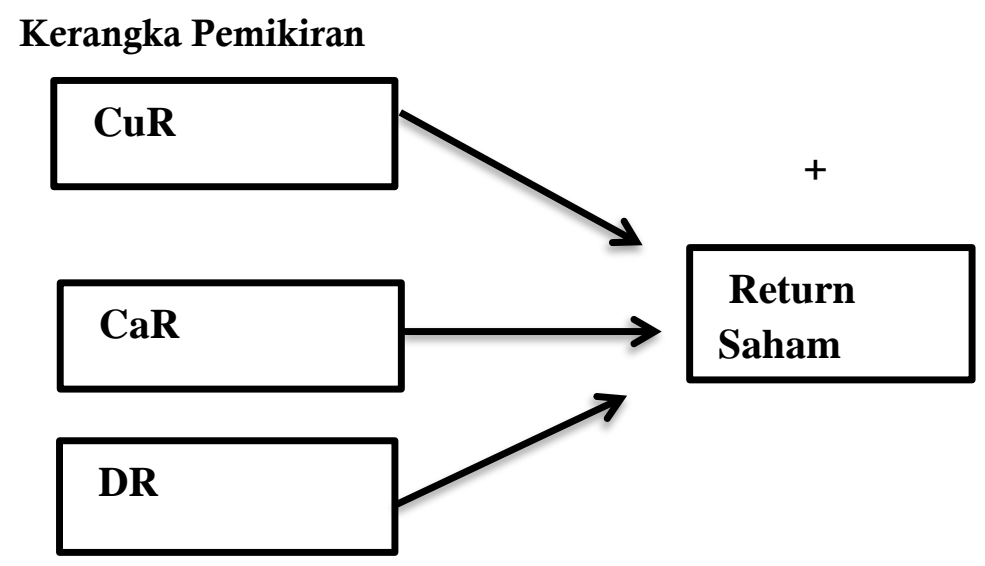

Pengembangan Hipotesis

Current Ratio (CuR) menunjukkan kemampuan perusahaan dalam memenuhi kewajiban jangka pendek dan membiayai kegiatan operasional, jika perusahaan dapat membiayai kegiatan operasionalnya dengan baik maka investor akan lebih tertarik kepada perusahaan tersebut. CuR yang tinggi menunjukkan perusahaan dalam kondisi liquid, perusahaan yang liquid lebih menarik minat investor. Jika banyak investor yang tertarik membeli saham perusahaan tersebut, maka harga saham dari perusahaan itu akan naik dan return saham dari perusahaan tersebut juga akan meningkat. Sehingga Current ratio dan return saham memiliki hubungan yang positif (+), hal ini sesuai dengan penelitian dari Ulupui (2005) dan Astuti (2006). Dari uraian di atas dan penelitian terdahulu maka dapat diusulkan sebuah hipotesis sebagai berikut;

$\mathrm{H} 1$ : CuR berpengaruh positif terhadap return saham.

Cash Ratio (CaR) adalah salah satu ukuran dari rasio likuiditas (Liquidity Ratio) yang merupakan kemampuan perusahaan memenuhi kewajiban jangka pendeknya (current liability) melalui sejumlah kas (dan setara kas, seperti giro atau simpanan lain di bank yang dapat ditarik setiap saat) yang dimiliki perusahaan. Semakin tinggi Cash Ratio menunjukan kemampuan kas perusahaan untuk memenuhi kewajiban jangka pendeknya. Hal ini juga sejalan dengan teori Bird in the Hand yang dinyatakan Myron Gordon dan John Litner (1956) dengan menyatakan investor lebih merasa aman untuk memperoleh pendapatan berupa pembayaran dividen daripada menunggu capital gain $\mathrm{H} 2$ : CaR berpengaruh positif terhadap return saham.

Debt Ratio (DR) menunjukkan tingkat hutang perusahaan. Perusahaan dengan hutang yang besar mempunyai biaya hutang yang besar pula. Hal tersebut menjadi beban bagi perusahaan yang dapat menurunkan tingkat kepercayaan investor. Jika sebuah perusahaan memiliki nilai DR yang tinggi maka perusahaan itu akan memiliki tingkat 
resiko yang tinggi pula, karena hutang yang ditanggung perusahaan juga semakin tinggi, semakin besar nilai dari rasio DR menunjukkan semakin besar kewajiban yang harus ditanggung oleh perusahaan. Para investor lebih memilih perusahaan yang memiliki nilai rasio DR yang rendah, karena hal ini menunjukkan kewajiban yang ditanggung perusahaan juga semakin kecil.

H3 : DR berpengaruh positif terhadap return saham.

\section{METODE PENELITIAN}

\section{Jenis Penelitian}

Sesuai dengan masalah dan tujuan yang dirumuskan, maka penelitian ini tergolong penelitian kuantitatif. Penelitian kuantitatif deskriptif sendiri merupakan penelitian yang berbentuk angka. Menggunakan metode deskriptif yang bersifat kuantitatif karena penelitian ini berkaitan dengan objek penelitian yaitu pada perusahaan dengan kurun waktu tertentu dengan mengumpulkan data dan informasi yang berkaitan dengan perusahaan dan disesuaikan dengan tujuan penelitian. Informasi yang telah diperoleh, selanjutnya dilengkapi dengan perubahan dari penulis sendiri, pelaksanaan metodemetode deskriptif tidak terbatas hanya pada pengumpulan data, tetapi meliputi analisis dan interpretasi tentang arti data tersebut.

\section{Populasi dan Sampel}

Dalam penelitian ini populasinya adalah perusahaan-perusahaan BUMN yang terdaftar di BEI. Populasi adalah semua individu atau unit-unit yang menjadi objek penelitian Sedangkan "sampel adalah sebagian dari jumlah dan karakteristik yang dimiliki oleh populasi tersebut". Sampel merupakan bagian dari populasi yang ingin di teliti oleh peneliti. Adapun pertimbangan pengambilan sampel tersebut adalah :

a) Perusahaan BUMN

b) Perusahaan BUMN yang tidak terdaftar di Bursa Efek Indonesia periode dan tidak menyediakan laporan tahunan lengkap / informasi mengenai tanggung jawab sosial perusahaan pada periode 2015, 2016, 2017,2018, dan 2019.

c) Saham perusahaan dari perusahaan BUMN listing BEI aktif diperdagangkan selama periode 2015-2019.

\section{Metode Pengumpulan Data}

Dalam teknik pengambilan sampel ini penulis menggunakan teknik sampling purposive. Sugiyono (2011:84) menjelaskan bahwa: "Sampling Purposive adalah teknik penentuan sampel dengan pertimbangan tertentu." Dari pengertian diatas agar memudahkan penelitian, penulis menetapkan sifat-sifat dan katakteristik yang digunakan dalam penelitian ini. Sampel yang akan digunakan peneliti memiliki ketentuan, laporan kinerja perusahaan-perusahaan BUMN yang terdaftar di BEI periode 2015-2019.

\section{Definisi Operasional dan Pengukuran Variabel.}

Dalam penelitian ini, penulis menggunakan satu variabel dependen dan tiga metode indepeneden. Variabel Dependen ( $\mathrm{Y}$ ) yang diguanakan adalah sedangkan variabel independen $(\mathrm{X})$ adalah Kinerja keuangan yang mennggunakan perhitungan rasio, perputaran persediaan, perputaran aktiva tetap, dan perputaran total aktiva.

1. Variabel (Y) Return Saham

Return Saham $=$

Pt-Pt-1

2. Variabel (X)

$$
\text { Pt-1 }
$$

\section{Financial \\ Performance and \\ Stock Return}

\section{a. Current Ratio (X1)}

\section{Current Ratio $=$ Aktiva Lancar \\ b. Cash Ratio (X2) \\ Hutang lancar}

Cash Ratio $=\frac{\text { Kas }+ \text { Setara Kas }}{\text { Hutang Lancar }}$ 
Financial

Performance and

Stock Return

$\underline{428}$ c. Debt Ratio(X3)

Debt Ratio =

\section{Total Hutang \\ Total Aktiva}

\section{Jenis Dan Sumber Data}

Untuk membantu penulis dalam melakukan penelitian ini, penulis menggunakan jenis data sekunder. Data sekunder merupakan sumber data penelitian yang diperoleh secara tidak langsung atau melalui media perantara (diperoleh dan dicatat oleh pihak lain). Sumber data penelitian ini diperoleh melalui Indonesian Capital Market Directory (ICMD), situs resmi BEI yaitu www.idx.co.id, dan website resmi perusahaan, seperti data lokasi perusahaan, sejarah singkat perusahaan, struktur organisasi, visi dan misi perusahaan.

\section{Teknik Pengumpulan Data}

Dalam penelitian ini, penulis menggunakan teknik dokumenter dengan melihat laporan keuangan perusahaan sampel. Dengan teknik ini penulis mengumpulkan data laporan keuangan perusahaan BUMN yang terdaftar di Bursa Efek Indonesia dari tahun 2015 2019 yang memuat informasi mengenai rasio kinerja keuangan BUMN (rasio lancar, rasio kas, dan rasio hutang), terhadap return saham yang berpengaruh terhadap kinerja keuangan perusahaan. Data keuangan diperoleh melalui ICMD, situs resmi Bursa Efek Indonesia.

\section{Teknik Analisis Data}

Penelitian ini menggunakan teknik analisis deskriptif, artinya data yang diperoleh yaitu laporan keuangan yang di publikasikan pada laman Bursa Efek Indonesia selama periode 2015-2019 yang memuat informasi mengenai rasio aktivitas kinerja keuangan BUMN yang diolah sedemikian rupa sehingga memberikan data yang sistematis, faktual dan akurat mengenai permasalahan yang diteliti, mengambarkan dan menginterprestasi objek sesuai dengan apa adanya (Imam 2009 :19). Akan dianalisis antara kinerja keuangan yang diukur menggunakan analisis Rasio Keuangan kemudian melihat pengaruhnya terhadap return saham.

\section{Jenis Pengujian}

Pengujian Hipotesis Uji parsial (Uji t)

a. Menurut Ghozali (2007) uji stastistik t pada dasarnya menunjukkan seberapa jauh pengaruh satu variabel independen secara individual dalam menerangkan variabel dependen. Pengujian dilakukan dengan menggunakan significance level 0,05 $(a=5 \%)$. Penerimaan atau penolakan hipotesis dilakukan dengan kriteria sebagai berikut: Jika a $>0,05$ maka hipotesis ditolak (koefisien regresi tidak signifikan. Sebaliknya jika a $\leq$ 0,05 maka hipotesis diterima atau Ho ditolak (koefisien regresi signifikan). Ini berarti secara parsial variabel independen tersebut mem- punyai pengaruh yang signifikan terhadap variabel dependen.

\section{HASIL DAN PEMBAHASAN \\ Statistik Deskriptif}

Statistik deskriptif bertujuan untuk mengetahui karakteristik dari sampel yang digunakan tabel 1. Berdasarkan tabel 1 diketahui bahwa dari 98 data yang ada, nilai minimum variabel Current Ratio adalah 0,4 \% yang terdapat pada PT Garuda Indonesia tahun 2019 , nilai maximum variabel current ratio sebesar 5,7\% terdapat pada PT KAEF tahun 2017. Nilai rata-rata variabel Current ratio adalah 1,36 \% terdapat pada PT Adhi Karya, dengan nilai standard deviasi sebesar $0,82 \%$. Dari hasil tersebut dapat di simpulkan bahwa nilai rata-rata variabel Current ratio lebih kecil dari nilai signifikan, jadi dapat dikatakan bahwa itu buruk.

Nilai pada variabel Cash Ratio memiliki nilai minimum $0,5 \%$ yang terdapat pada PT Krakatau Steel tahun 2019 , nilai maxsimun 14,6 \% terdapat pada Bank Mandiri tahun 2016, dan nilai rata-rata 1,52 \% .Dengan standar deviasi $2,43 \%$. Output SPSS 
menunjukkan DR memiliki nilai rata-rata 1.379 dengan nilai minimum 0,09 dan nilai maksimum 12,24.

Return saham memiliki nilai rata-rata (mean) sebesar 0,00249. Return saham maximum sebesar 0,1469 yang berarti bahwa sampel tertinggi mempunyai tingkat pengaruh informasi sebesar $14,6 \%$ dan return saham minimum sebesar $-0,134$ yang berarti bahwa sampel terendah mempunyai tingkat pengaruh informasi sebesar 13,4\%.

\section{Uji Regresi Berganda}

penelitian ini menggunakan model regresi yang berbeda untuk menguji pengaruh Kinerja keuangan yaitu dengan model regresi berganda dari variabel independen. Sehingga rumus

\section{Financial}

Performance and Stock Return persamaan regresinya menjadi:

$\mathrm{Y}($ Returns $)=\mathrm{a}+\mathrm{b} 1(\mathrm{CuR})+\mathrm{b} 2(\mathrm{CaR})+\mathrm{b} 3(\mathrm{DR})+\mathrm{e}$

$\mathrm{Y}=-0,021+0,012 \mathrm{X} 1+0,004 \mathrm{X} 2+0,002 \mathrm{X} 3$.

Tabel 1. Uji Statistik Deskriptif

\begin{tabular}{|l|l|l|l|l|l|}
\hline & $\mathrm{N}$ & Minimum & Maximum & Mean & Std. Deviation \\
\hline Current Ratio & 98 & .04 & 5.71 & 13.615 & .82052 \\
\hline Cash Ratio & 98 & .05 & 14.60 & 15.272 & 243.117 \\
\hline Debt Ratio & 98 & .09 & 12.24 & .8432 & 137.978 \\
\hline Return Saham & 98 & -.1342 & .1469 & .002499 & .0416223 \\
\hline Vakid N (listwise) & 98 & & & & \\
\hline
\end{tabular}

Tabel 2. Uji Regresi Berganda

\begin{tabular}{|c|l|r|r|r|r|r|}
\hline \multirow{2}{*}{ Model } & \multicolumn{2}{|c|}{$\begin{array}{c}\text { Unstandardized } \\
\text { Coefficients }\end{array}$} & $\begin{array}{c}\text { Standardized } \\
\text { Coefficients }\end{array}$ & \multirow{2}{*}{$\mathrm{T}$} & \multirow{2}{*}{ Sig. } \\
\cline { 2 - 7 } \multicolumn{2}{|c|}{} & B & Std. Error & \multicolumn{1}{c|}{ Beta } & & \\
\hline \multirow{4}{*}{1} & (Constant) & -.021 & .009 & & -2.218 & .029 \\
\cline { 2 - 7 } & Current Ratio & .012 & .005 & .238 & 2.364 & .020 \\
\cline { 2 - 7 } & Cash Ratio & .004 & .002 & .206 & 2.072 & .041 \\
\cline { 2 - 7 } & Debt Ratio & .002 & .003 & .056 & .560 & .577 \\
\hline
\end{tabular}

Current Ratio (CuR) sebesar 0,012. Nilai koefisien yang positif menunjukkan bahwa CuR berpengaruh positif terhadap return saham perusahaan BUMN yang listing Bursa Efek Indonesia tahun pengamatan 2015-2019. Hal ini menunjukkan bahwa setiap 1\% dari rasio lancar (CuR) akan menyebabkan kenaikan harga saham yang diterima sebesar nilai koefisien.

Cash Ratio (CaR) sebesar 0,04. Nilai koefisien yang positif menunjukkan bahwa $\mathrm{CaR}$ berpengaruh positif terhadap return saham perusahaan BUMN yang terdaftar di BEI tahun pengamatan 2015-2019, menunjukkan bahwa setiap kenaikan 1\% dari rasio kas (CaR) akan menyebabkan kenaikan harga saham yang diterima sebesar nilai koefisiensi.

Debt Ratio (DR) sebesar 0,02. Nilai koefisien yang positif menunjukkan bahwa DR berpengaruh positif terhadap return saham perusahaan BUMN yang terdaftar di BEI tahun pengamatan 2015-2019. Hal ini menunjukkan bahwa setiap kenaikan 1\% dari rasio hutang (DR) akan menyebabkan kenaikan harga saham yang diterima sebesar nilai koefisiensi.

\section{Hasil Pengujian Uji T}

a. Uji Hipotesis $1(\mathrm{H} 1)$

Nilai t-hitung current ratio sebesar 2,364 dan probabilitas sebesar 0,020 yang nilainya lebih kecil dari taraf signifikansi 0,05, maka dapat di ambil kesimpulan bahwa Current Ratio secara parsial berpengaruh signifikan terhadap return saham.

b. Uji Hipotesis $2(\mathrm{H} 2)$

Nilai t-hitung cash ratio sebesar 2,072 dan probabilitas sebesar 0,041 yang nilainya lebih kecil dari taraf signifikansi 0,05, maka dapat disimpulkan bahwa Cash Ratio secara parsial berpengaruh signifikan terhadap return saham. 
Financial

Performance and

Stock Return

c. Uji Hipotesis $3(\mathrm{H} 3)$

Nilai t-hitung debt ratio sebesar 0,560 dan probabilitas sebesar 0,577 yang nilainya lebih besar dari taraf signifikansi 0,05 , maka debt ratio secara parsial tidak berpengaruh signifikan terhadap return saham.

\section{Pengaruh Current Ratio, Cash Ratio, dan Debt Ratio terhadap Return Saham secara Simultan}

Hasil analisis statistik untuk variabel current ratio, cash ratio, debt ratio secara simultan menunjukkan sig F sebesar 0,034 <0,05 maka Ha diterima dan menolak Ho (hipotesis ditolak). Ini menunjukkan bahwa current ratio, cash ratio, dan debt ratio secara bersama-sama berpengaruh secara signifikan terhadap return saham pada perusahaan BUMN yang terdaftar di BEI periode 2015-2019, sehingga hipotesis keempat diterima. Nilai koefisien determinasi (R2) yang diperoleh sebesar koefisien determinasi $r$ square (R2) sebesar 0,088 menunjukkan bahwa 8,8\% return saham dipengaruhi oleh variabel current ratio, cash ratio, dan Debt ratio, sedangkan 91,2\% dijelaskan oleh faktor lain. Dari hasil analisis statistik tersebut, maka dapat disimpulkan bahwa CuR, CaR, dan DR secara simultan memiliki pengaruh positif terhadap Return Saham pada perusahaan BUMN yang terdaftar di BEI periode 2015-2019.

\section{PENUTUP}

Penelitian ini dilakukan untuk menguji Pengaruh CuR, CaR, dan DR Terhadap Return Saham 20 Perusahaan BUMN Di Bursa Efek Indonesia pada tahun 2015-2019. Dari hasil analisis data, pengujian hipotesis, dan pembahasan, maka dapat ditarik kesimpulan dari penelitian ini sebagai berikut:

1. Current Ratio memiliki pengaruh positif dan signifikan terhadap return saham perusahaan BUMN yang terdaftar di Bursa Efek Indonesia.

2. Cash Ratio berpengaruh positif dan signifikan terhadap return saham perusahaan BUMN yang terdaftar di Bursa Efek Indonesia.

3. Debt Ratio berpengaruh negatif dan signifikan terhadap return saham perusahaan BUMN yang terdaftar di Bursa Efek Indonesia.

Beberapa kerbatasan sebagai berikut

1. Variabel independen dalam penelitian ini menggunakan current ratio, cash ratio, dan debt ratio, dimana rasio tersebut memiliki pemaknaan yang sama dengan ukuran yang berbeda.

2. Penelitian dilakukan pada periode 2015-2019, sehingga belum mampu memberikan gambaran yang lebih komprehensif terhadap hasil penelitian.

3. Keterbatasan dalam mengambil variabel yang digunakan dalam variabel penelitian, yaitu hanya terbatas pada variabel-variabel akuntansi saja dengan tidak melibatkan faktor ekonomi makro seperti gejala resesi ekonomi dunia, tingkat suku bunga, inflasi dan lain-lain.

4. Beberapa penelitian belum pernah ada yang menggunakan cash Ratio dan debt ratio, sehingga untuk mendapatkan acuan tentang return saham sangat terbatas.

Berdasarkan hasil pembahasan, maka rekomendasi yang dapat disampaikan adalah sebagai berikut:

1. Bagi manjer perusahaan BUMN perlu meningkatkan kinerjanya menjadi lebih efisien dan produktif, seperti dalam hal melakukan kewajibanya.

2. Bagi Investor, semoga penelitian ini menjadi bahan pertimbangan dalam pengambialan keputusan untuk melakukan investasi dengan melihat Current Ratio, Cash Ratio, Debt Ratio terhadap Return Saham.

3. Penelitian selanjutnya diharapkan dapat menambah variabel-variabel penelitian yang lain seperti, Ukuran perusahaan, leverage, harga saham dan lain sebagainya.

4. Periode waktu yang digunakan selama 5 tahun masih terlalu singkat. Untuk peneliti selanjutnya dapat menambah periode waktu yang lebih lama agar hasil penelitian yang lebih akurat dan dapat menggambarkan keadaan secara menyeluruh perusahaan BUMN go public di Indonesia . 
5. Rasio pengukur yang digunakan masih terlalu sedikit. Untuk peneliti selanjutnya dapat menambah rasio-rasio yang lebih banyak agar hasil penelitian yang lebih akurat dan dapat menggambarkan keadaan secara menyeluruh perusahaan BUMN yang listing BEI.

6. Perusahaan yang di gunakan sebagai sampel masih sangat sedikit, penelitian selanjutnya sebaiknya menambah data sampel perusahaan, misal pada bidang manufaktur atau yang lainnya

\section{DAFTAR PUSTAKA}

Ang, Robert .1997. Buku Pintar Pasar Modal Indonesia.Jakarta:Media Staff Indonesia Agustianawati, P. and Puspitasari, R., 2018. Stock Performance Analysis (Case Study PT ERATEX DJAJA, Tbk-ERTX). In THE INTERNATIONAL CONFERENCE ON ACCOUNTING AND MANAGEMENT SCIENCE (p. 107).

Bisara, Chrismas. 2015. Pengaruh Kinerja Keuangan, Surabaya : STIE Indonesia.

Bursa Efek Indonesia, Laporan Keuangan Tahunan 2015, 2016, 2017, 2018, dan 2019. (diakses di http://www.idx.co.id)

Darajat, Zakiah. 2018. Skripsi Pengaruh ROA, EPS, dan DERTerhadap Return Saham. Yogyakarta: UNY.

Djanegara, M.S., 2017. Pengaruh Kualitas Audit Terhadap Kualitas Laporan Keuangan Pemerintah Daerah. Jurnal Akuntansi, 21(3), pp.461-483.

Ghozali, Imam. 2016. Aplikasi Analisis Multivariete Dengan Program IBM SPSS 23 (Edisi 8). Cetakan ke VIII. Semarang : Badan Penerbit Universitas Diponegoro.

Gordon, Myron and John Lintner. 1956. Distrribution of Income of Corporations Among Dividend, Retained Earning and Taxes. The American Economic Review.

Harahap, Sofyan Syafri. 2015 . Analisis Kritis atas Laporan Keuangan. Edisi 1-10. Jakarta: Rajawali Pers.

Hidayat, L., Muktiadji, N. and Supriadi, Y., 2020, May. The Knowledge and Students' Interest to Investing in Investment Gallery. In 2nd International Seminar on Business, Economics, Social Science and Technology (ISBEST 2019) (pp. 142-145). Atlantis Press.

I.G.K.A Ulupui. 2005. .Analisis Pengaruh Rasio Likuiditas, Leverage, Aktivitas dan Probabilitas Terhadap Return Saham (Studi Pada Perusahaan Makanan dan Minuman dengan Kategori Industri Barang Konsumsi di BEI,Jurnal Akuntansi Fakultas Ekonomi, Universitas Udayana.

Iriyadi, I., Maulana, M.A. and Nurjanah, Y., 2018, December. Financial Reporting for Micro Small and Medium Enterprises Towards Industrial Revolution Era 4.0. In International Conference On Accounting And Management Science 2018 (pp. 32-38).

Kasmir. 2016 . Analisis Laporan Keuangan. Jakarta: Raja Grafindo Persada.

Kusumawardani, Dwi Sesanti. 2014 . Pengaruh Kinerja Keuangan Perusahaan. Malang : Fakultas Ilmu Administrasi Universitas Bramawijaya.

Muanas, M. and Mulia, I., 2020. Pendampingan Penguasaan Akuntansi Dasar Bagi Pegawai BPR Mitra Daya Mandiri Bogor. Jurnal Abdimas Dedikasi Kesatuan, 1(1), pp.51-56.

Murdihardjo, L., Nurjanah, Y. and Rendy, R., 2020, May. Implementing INTACS Dynamics Enterprise Resources Planning System for Financial Statements. In 2nd International Seminar on Business, Economics, Social Science and Technology (ISBEST 2019) (pp. 228-233). Atlantis Press.

Nugroho, Bramantyo. 2012. Pengaruh Kinerja Keuangan Terhadap Return Saham. Semarang: Universitas Diponegoro.

Pramiudi, U. and Setiawan, B., 2019. Penelusuran Persepsi Mahasiswa Atas Program Studi Akuntansi dan Minat Studi Lanjut. JAS-PT (Jurnal Analisis Sistem Pendidikan Tinggi Indonesia), 2(2), pp.103-113.

\section{Financial \\ Performance and \\ Stock Return}

431 
Financial

Performance and Stock Return

432
Sudradjat, S. and Djanegara, M.S., 2020. PKM Uji Kompetensi Bidang Keahlian Akuntansi Di SMK Bina Sejahtera Kota Bogor. Jurnal Abdimas Dedikasi Kesatuan, 1(1), pp.21-28.

Ulupui, IGKA. 2007 . Analisis Pengaruh Rasio Likuiditas, Leverage, Aktivitas dan Profitabilitas Saham pada Perusahaan Makanan dan Minuman Dengan Kategori Industri Barang Konsumsi di BEI. Jurnal BEI. Jurnal Akuntansi dan Bisnis Yahya, Ariani Dwi. 2018. Pengaruh Rasio Keuangan Terhadap Pertumbuhan Manajemen Laba Pada PT Krakatau Steel. Banten : STIE Bina Bangsa.

https://eprints.uny.ac.id/23896/5/5.\%20BAB\%20III.pdf di akses tanggal 20 Juli 2020).

https://guruakuntansi.co.id/rasio-keuangan/ di akses tanggal 1 Juli 2020

https://nusantaranews.wordpress.com/2009/06/26/sejarah-bumn-imf-word-bank-danprivatisasi-di-indonesia-1/. di akses tanggal 20 Juni 2020

https://www.kompasiana.com/faisalbasri/54fdd5f5a33311c821510378/latar-belakangkeberadaan-bumn. di akses tanggal 15 Juli 2020. 